\section{Fluorescence In Situ Hybridization on Sperm Using Alkaline Denaturation}

\section{BioTechniques 33:266-267 (August 2002)}

Fluorescence in situ hybridization (FISH) permits the detection of unique DNA sequences of target DNA within single cells. FISH allows the identification of DNA sequences within individual cells and readily identifies genetic changes within a mixed population of cells. However, problems arise in maintaining nuclear morphology, particularly following harsh denaturation procedures where cells are heated to $80^{\circ} \mathrm{C}$, causing the nuclear boundary to become blurred or the cell to completely burst. In an attempt to preserve cellular morphology and high hybridization efficiency, particularly in fresh tissue samples, we evaluated a FISH protocol using alkaline denaturation in place of heat. In addition, heat denaturation requires that the cells be aged at $-20^{\circ} \mathrm{C}$ for $24 \mathrm{~h}$, whereas alkaline denaturation can be performed immediately on fresh tissue samples. This is particularly im portant in diagnostic settings, when rapid results are desired. Changing to an alkaline denaturation protocol would save at least $24 \mathrm{~h}$.

Alkaline denaturation is the method of choice for denaturing DNA for later attachment to nitrocellulose or nylon membranes during Southern blot analysis (3). Alkaline denaturation is less harsh on cells than heat denaturation. We evaluated its use in denaturation of target DNA from fresh tissues. We achieved efficient, reproducible hybridization signals and maintained cellular integrity in fresh sperm cells.

We describe the application of alkaline denaturation to the FISH technique in sperm from normal control donors. We used alkaline denaturation and FISH on fresh sperm cells to determine aneuploidy and whether we could maintain cellular integrity.

Sperm were decondensed using dithiothreitol as previously described (2). Aneuploidy was scored using the criteria of Martin and Rademaker (1). All slides were stored at $4^{\circ} \mathrm{C}$ for short-term storage or at $-20^{\circ} \mathrm{C}$ for long-term storage.

Before FISH, the samples (affixed to microscope slides) were denatured for $3 \mathrm{~min}$ in denaturation solution $(1.5 \mathrm{M}$ $\mathrm{NaCl}, 0.5 \mathrm{M} \mathrm{NaOH})$ at room temperature, followed by neutralization for 3 min in a solution of $0.5 \mathrm{M}$ Tris- $\mathrm{HCl}, \mathrm{pH}$ 7.0, $3.0 \mathrm{M} \mathrm{NaCl}$ at room temperature. The slides were washed for $3 \mathrm{~min}$ in $2 \times$ $\mathrm{SSC}, \mathrm{pH} 7.0$, and dehydrated in icecold ethanol $(50 \%, 70 \%$, and $95 \%)$ for 3 min each at $-20^{\circ} \mathrm{C}$.

Twenty nanograms of each $\alpha$ satellite DNA plasmid clone were dissolved in $50 \%-65 \%$ formamide, $2 \times \mathrm{SSC}$ with $10 \%$ dextran sulfate in a total volume of $10 \mu \mathrm{L}$. The probe mixture was denatured at $80^{\circ} \mathrm{C}$ for $5 \mathrm{~min}$ on a heat block
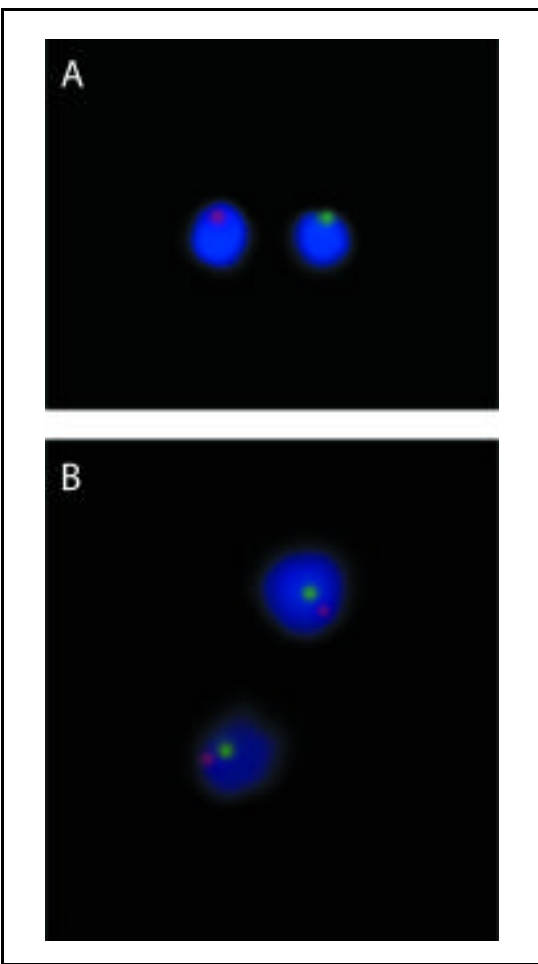

Figure 1. Comparison of alkaline denaturation (A) to heat denaturation (B). (A) Fresh sperm cells hybridized via alkaline denaturation with two-probe, two-color FISH for chromosomes X (FITC, green) and Y (Rhodamine, red) with the nuclei counterstained in DAPI (blue). (B) Sperm cells hybridized via heat denaturation with twoprobe, two-color FISH for chromosomes 7 (FITC, green) and 8 (Rhodamine, red) with the nuclei counterstained in DAPI (blue). The cell in the low er left-hand corner (B) shows blurred, uneven, and damaged nuclear perimeter. Nuclear morphology is superior in fresh samples hybridized by alkaline denaturation (A) when compared to samples hybridized by heat denaturation (B). Stringency washes were optimized in our laboratory for use with DNA probes for all chromosomes. and cooled on ice. Immediately follow ing probe mixture denaturation, the dehydrated slides were air-dried and the denatured probe mixture was applied. The slides were hybridized at $37^{\circ} \mathrm{C}$ $42^{\circ} \mathrm{C}$ for $15 \mathrm{~min}$ up to $24 \mathrm{~h}$.

Following hybridization, stringency washes included three washes in $50 \%$ formamide $/ 2 \times \mathrm{SSC}, \mathrm{pH} 7.0$, for $5 \mathrm{~min}$ each at $37^{\circ} \mathrm{C}-45^{\circ} \mathrm{C} ; 2 \times \mathrm{SSC}, \mathrm{pH} 7.0$, for $5 \mathrm{~min}$ at $37^{\circ} \mathrm{C}-45^{\circ} \mathrm{C}$; and a $5-\mathrm{min}$ wash in $4 \times \mathrm{SSC} / 0.05 \%$ Tween ${ }^{\circledR} 20, \mathrm{pH}$ 7.0 , at $37^{\circ} \mathrm{C}-45^{\circ} \mathrm{C}$. Cells were counterstained with DAPI (500 ng/mL). Stringency washes were optimized in our laboratory for use with DNA probes for all chromosomes.

Control donor semen samples denatured using alkaline denaturation showed no statistically significant difference in the level of aneuploidy (data not shown) for chromosomes $\mathrm{X}, \mathrm{Y}$, and 18 versus the control specimens undergoing heat denaturation. Cells undergoing alkaline denaturation had excellent cell morphology with a high FISH efficiency (Figure 1).

Alkaline denaturation is a rapid technique that permits FISH analysis on fresh tissue without the loss of nuclear morphology. We have shown that efficiency, as measured by the level of aneuploidy, is similar between cells undergoing heat denaturation and those undergoing alkaline denaturation in fresh tissue samples. However, alkaline denaturation maintains a high level of cellular and nuclear membrane integrity, making alkaline denaturation the method of choice for use with fresh tissue samples.

\section{REFERENCES}

1.Martin, R.H. and R.A. Rademaker. 1995. Reliability of aneuploidy estimates in human sperm: results of fluorescence in situ hybridization studies using two different scoring criteria. Mol. Reprod. Dev. 42:89-93.

2.Pang, M.G., J.L. Zackowski, S.F. Hoegerman, E. Friedman, S.Y. Moon, A.J. Cuticchia, A.A. Acosta, and W.G. Kearns. 1995. Detection of fluorescence in situ hybridization of chromosome 4,6,7,8,9,10,11, $12,13,17,18,21, \mathrm{X}$ and $\mathrm{Y}$ aneuploidy in sperm from oligo-astheno-terato-zoospermic patients of an in vitro fertilization program. Am. J. Hum. Genet. 57:680.

3.Sambrook, J., E.F. Fritsch, and T. Maniatis. 1989. Molecular Cloning: A Laboratory Manual, 2nd ed. CSH Laboratory Press. Cold Spring Harbor, NY. 
Address correspondence to Dr. Laura Aridgides, Center for Pediatric Research, 855 West Brambleton Avenue, Norfolk, VA 23510,USA.e-mail:aridgilj@chkd.com

Received 7 December 2001; accepted 10 April 2002.

L.J. Aridgides, M. Stacey, L. Brihn, D. Scott, and C. Osgood Center for Pediatric Research Eastern Virginia Medical School Norfolk, VA, USA

\section{Tandem Affinity Purifica- tion of Protein Complexes from Mammalian Cells}

\author{
BioTechniques 33:267-270 (August 2002)
}

Proteomics promises to deliver answers to complex biological questions by gaining insight into the function of proteins within the cellular environment. One of the major challenges facing proteomics researchers is to define the interactions between proteins involved in higher-order complexes within the cell. To date, the spotlight has focused mostly on advances in mass spectrometry, with better sensitivity, higher resolution, and more confident assignments of protein identifications $(1,8)$. The technology to purify proteins and their "interacting partners" still relies on traditional methods of protein purification, and there has been little advancement in these methods to match the gains made in mass spectrometry.

Some excellent large-scale proteomics research has been demonstrated lately; however, even these efforts have predominantly identified highly abundant proteins $(7,12)$. The lowabundance proteins are often available in limiting amounts and are vital for the regulation of key cellular processes such as cell growth, differentiation, and adaptation. Identification of these pro- teins from whole cell extracts is often nearly impossible, as these scarce proteins are masked by the overwhelming amount of housekeeping and structural proteins. Many biological questions require a more targeted proteomics approach capable of identifying functional complexes of proteins. This approach requires the purification of a target protein under conditions that will allow it to co-purify with partners that it complexes with inside the cell. The use of antibodies or the incorporation of a peptide tag facilitates this purification; however, it is inevitable for some nonspecific proteins to contaminate the purification of the target protein and its functional partners. Often these nonspecifically interacting proteins will mask important functional partners.

Recently, researchers have developed a tandem affinity purification (TAP) scheme and demonstrated its usefulness in a yeast expression system $(10,11)$. This tag consists of two IgG binding units of protein A from Staphylococcus aureus and a calmodulin bind- ing peptide (CBP), separated by a specific TEV protease cleavage site. Purification of a tagged protein involves lysis under nondenaturing conditions and binding to rabbit IgG agarose beads. Protease cleavage of the protein A tag releases the target protein with its $\mathrm{CBP}$ tag, which is subsequently bound to calmodulin cross-linked beads. After washing, the protein is then eluted using EGTA.

This method has proved very useful in probing a number of protein com plexes in yeast $(2,3,5,6)$. Here we demonstrate the utility of this method in a mammalian cell culture system. Members of the myocyte enhancer factor 2 family (MEF2) form homo- and heterodimers to become potent regulators of muscle gene transcription $(4,9)$. Here we report the utility of using a TAP-tagged MEF2-A regulatory protein to co-purify its heterodimeric partner, MEF2-C, from mammalian cells.

To facilitate the production of TAPtagged proteins in mammalian cells, the coding region for an $\mathrm{N}$-terminal TAP

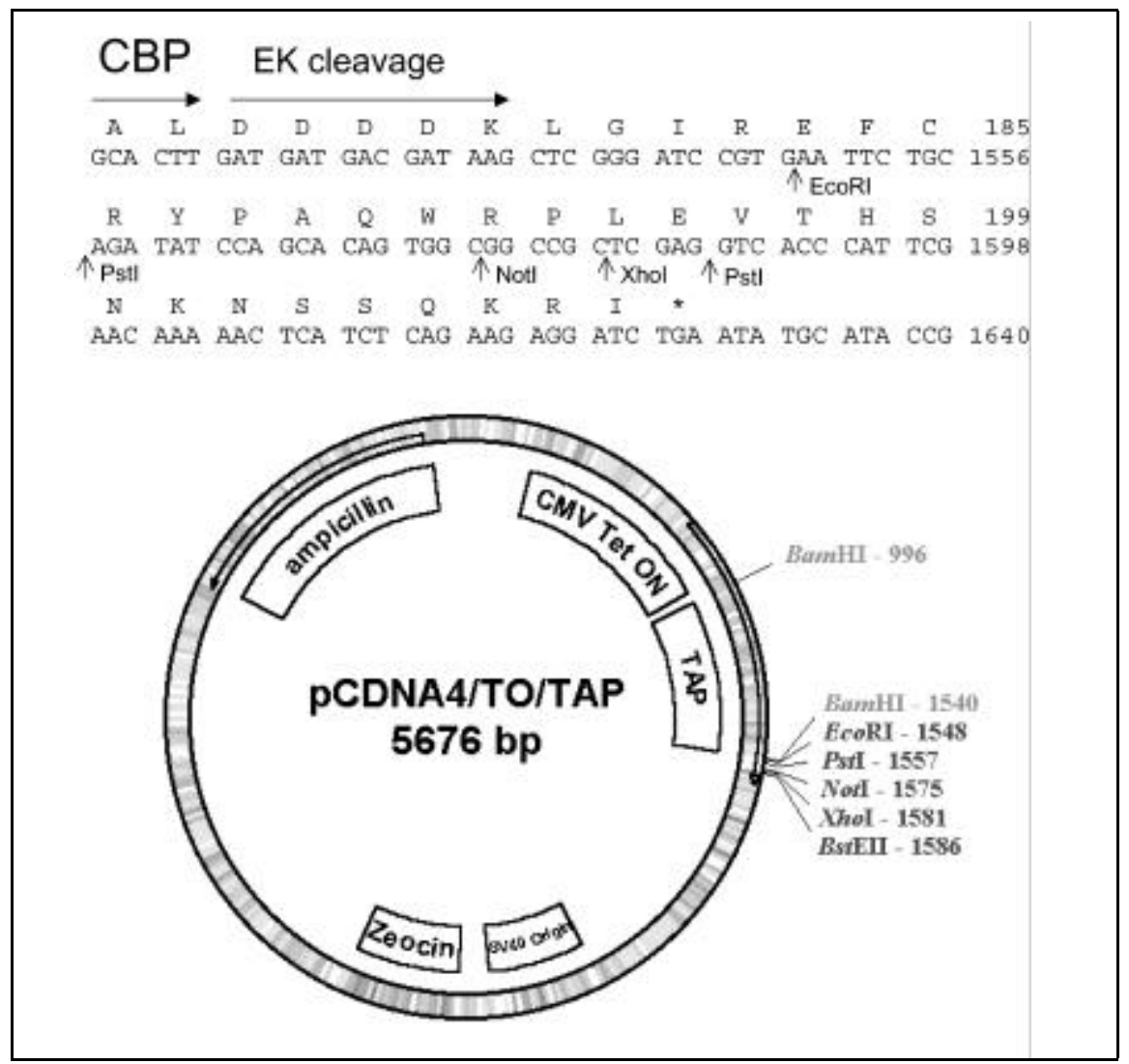

Figure 1. The N-terminal TAP tag in a mammalian expression system. TO, tetracycline-regulated expression; EK, enterokinase. 